\title{
Reconsidering Sustainable Mobility Patterns in Cultural Route Planning: Andreas Syngrou Avenue, Greece
}

\author{
Efthimios Bakogiannis ${ }^{\dagger}$, Charalampos Kyriakidis ${ }^{\dagger}{ }^{*}$, Maria Siti $^{\dagger}$ and Eleni Floropoulou $^{\dagger}$ \\ Department of Geography and Regional Planning, School of Rural and Surveying Engineering, National \\ Technical University of Athens (NTUA), Heroon Polytechniou Str., 9, Zographou Campus, 15780 Athens, Greece; \\ ebako@mail.ntua.gr (E.B.); sitim.atm@gmail.com (M.S.); helenaflo@hotmail.com (E.F.) \\ * Correspondence: kyriakidisharry@gmail.com; Tel.: +30-210-772-11-53 \\ + These authors contributed equally to this work.
}

Received: 7 April 2019; Accepted: 12 June 2019; Published: 16 June 2019

\begin{abstract}
Culture is frequently used as a means of promoting sustainable urban development. Indeed, in many areas across Europe, cultural and recreational routes or clusters have so far been utilized in order for urban regeneration and structural reconstruction to be pursued. Such routes have been developed in Greek cities as well, e.g., in the cities of Volos, Thessaloniki, and Athens. In the Greek capital, Athens, a couple of axes are actually recognized as cultural ones. Andreas Syngrou Avenue, initially designed as a six/eight-lane freeway located at the heart of the Athens metropolitan area, is one distinguished example. By focusing on this axis as a cultural route/cluster, the goal of this article is to elaborate on smart and sustainable mobility patterns for strengthening its cultural/recreational identity and increasing its attractiveness. To accomplish this goal, critical problems confining citizens' mobility and access to various cultural landmarks in this area are identified and are properly dealt with, stressing the importance of sustainable mobility in relevant cultural planning endeavors. Based on the study and an assessment of the current state of this route (land uses, traffic loads, design qualities, and environmental affordances), a sustainable mobility proposal is provided in order for a master plan that enhances and develops the cultural function and identity of this route.
\end{abstract}

Keywords: cultural routes/clusters; sustainable mobility; urban regeneration; master plan; Andreas Syngrou Avenue

\section{Introduction}

In recent years, the term, urban regeneration, has emerged in order to describe a strategy, designed to address various urban and social issues which are due to, among others, economic recession and urban degradation [1-3]. Urban regeneration aims to ameliorate the aesthetics, safety, and livability of urban areas [4]. During the 1980s and the early 1990s, many projects addressing the above objectives were planned and implemented in various cities around the world [1,2,5,6]. As a result, a popular regeneration policy mechanism has now become the norm through the designation of cultural clusters $[7,8]$. Certainly, cultural aspects of each area are important drivers for urban planners, whose aim is the promotion of sustainable development $[9,10]$.

Regarding the approach to enhance cultural strategies through the revitalization of downgraded and abandoned urban areas, the theory of Bianchini [11] and Souliotis [12] has been observed and confirmed. In some cases, culture is used as a means of local economic policy, while in others it is used as "a strategy in its own right, to the globalization of capital and the political necessity to marshal all available resources in order to attract and hold international investment" [1] (p. 22). Such regeneration projects are usually planned and successfully implemented (as international experience 
shows, see Section 2), with their benefits extending beyond the social balance of the areas in which they are applied. Such benefits include the improvement of the quality of life and economic growth [13] through the transformation of culture into investment, leverage, income, employment [11], tourism [13], and recreation. Hence, it is apparent that the key aim of planners when culture is used as a 'vehicle' for urban regeneration is the promotion of cities' images at an international level, in times when cities compete with each other to attract more visitors, residents, and investments [14,15]. This goal may be achieved regardless of the way through which different cultural areas have emerged [11]. Mommaas [16] emphasizes the fact that cultural quarters appeared as: (a) Places left over after planning ('ploaps') and then turned into cultural sites by cultural managers, (b) places envisaged by cultural managers whose goal was to enhance the marketing power of these places within a competitive leisure and cultural market, and (c) on the drawing-board of urban planners who looked for ways to revitalize declined urban areas and boost the local creative economy.

The success of cultural areas depends on how much those goals can be achieved. Montgomery [7], when arguing on urban images and functions, states that the factors determining the success of cultural clusters are activity, form, and meaning. All three parameters are significantly affected by sustainable urban mobility planning, which is an emerging concept within the European transportation and urban planning agenda [17]. Sustainable mobility has spread positively in recent Greek projects.

Indeed, perceptions about space are changing, which is strongly reflected on the Greek strategic spatial planning system. Typical examples are the Spatial Plans of the Metropolitan Areas of Athens and Thessaloniki. In those plans, the need for investing in sustainable mobility infrastructure is underlined. In fact, in the Spatial Plan of the Athens Metropolitan Area, it is noted that sustainable mobility interventions can improve cultural competency through an enhancement of the cultural identity of an area by creating new cultural routes [18] and redesigning the streetscape. Nevertheless, this direction is superficially incorporated into the current legislative framework for the implementation of sustainable urban mobility plans (SUMPs) in Greece [19]. Highlighting landmarks and cultural activities is not one of the main parameters that planners should take into consideration when a SUMP is prepared. Instead, a general form of expression was chosen. According to that phrase, SUMPs should integrate, drive, and connect to the strategic planning guidelines. In this way, a direct link between the implementation of SUMPs and cultural regeneration policy seems not to be clearly recognized.

This paper explores how the implementation of SUMPs can enhance cultural strategies' potential and upgrade emerging cultural clusters. The key research question deals with the level of SUMP contribution in the emergence of successful cultural areas. This inquiry entails issues regarding the opportunities and abilities of SUMPs to both satisfy the needs of cultural clusters and also increase their visitation rate, thus turning them into popular places. However, it is important to consider whether and how the existence of cultural areas allows the implementation of sustainable mobility strategies and measures. Thus, the aim of the paper is: (a) to clarify the links between sustainable mobility planning and cultural areas' development, and (b) to set up a good practices guide to ensure the successful implementation of new plans of both types.

The aforementioned issues are examined through a case study in Athens (Section 3), regarding one of the most important arterial road axis (Andreas Syngrou and Vasileos Konstantinos Avenue), which connects Faliro bay with the city center of Athens, where important spots of cultural interest and historical value are located. These avenues are studied in order to plan a cultural urban corridor and apply sustainable mobility strategies through utilization of the international experience examined in Section 2. The research methodology (Section 3.2) is focused on an analysis of the current situation and formulation of a planning proposal. Based on the proposed interventions and analysis, this research evaluates the two key issues on SUMPs and culture clusters. The emerged conclusions (Section 5) confirm the matching of cultural strategies with the respective policies of sustainable mobility, thus underlying another important opportunity for currently car-centric Greek cities with a strong background in history and culture. 


\section{Review of Cultural Regeneration Case Studies}

Culture-led urban regeneration policies have been applied to many cities around the world; old and new, capital and provincial, large and small [20]. Certainly, the 1970s to 2000s period has witnessed the application of many urban regeneration strategies in post-industrial cities in North America and Western Europe, as well as Australia. More recently, developing countries and East Asian cities have also attempted such strategies [20-22]. It is remarkable that this wave of culture-led urban regeneration has spread from one country to another rather fast [21].

Typical examples are those of great cities in which famous clusters attract cultural entrepreneurs and artists, whether it is New York's Lower East Side, Soho and South Bank in London, or the Left Bank in Paris [7]. However, apart from cities of such scale, cities, like Pittsburgh in the USA, Manchester and Sheffield in the UK, Dublin in Ireland, Vienna in Austria, and Bilbao in Spain, have managed to become internationally known through the establishment and emergence of such areas. Indeed, areas, like the Pittsburg Cultural District, Manchester Northern Quarter, Sheffield Cultural Industries Quarter, Temple Bar, Vienna Museum Quarter, and the cultural area around the Guggenheim Museum in Bilbao, have succeeded in imprinting into people's consciousness as greatly successful landmarks, as Rodriguez and Martinez [23] point out. The aforementioned areas have based their development in a holistic and integrated planning model, placing an emphasis on the preservation of the historical memory and cultural heritage through the emergence of the areas' residential abundance and the planning of land use and activities. At the same time though, special emphasis was given to the presence of pedestrians and cyclists in the areas, although sustainable mobility was not such a trend at the time.

The relationship between sustainable mobility and the emergence of cultural areas is more evident in the cultural axes. In some cases, sustainable mobility strategies have been implemented to highlight already existing and redeveloped cultural sites, while in others both strategies are applied at the same time. Typical cases are the Cheong-Gye-Cheon River Renewal Project in Seoul, South Korea and the Highline Urban Trail in New York, USA.

The first case concerns the abolition of a 4-lane highway, about $6 \mathrm{~km}$ long with flyovers [24,25], which, combined with a 10-lane motorway [26], links the center of Seoul with the suburbs, and the restoration of the river. The river was filled with rubble in 1968 in order to provide a major arterial motorway to meet the needs of private motorized traffic [26,27]. The project was completed in 2005 and contributed to the development of a river-based linear park [28], which is an integral part of the history of Seoul $[29,30]$. The restoration of the river created a green oasis in the heart of the city through the establishment of an ecosystem within the urban space. The banks have extensive green and recreation areas, fountains, and cultural activities linked to pedestrian routes. The newly established walking routes drive citizens to walk more, while the motorway removal promotes the use of public transport [31]. The project sends the message for car use restriction in central areas of the city, at a time when the city is looking for a "balance between transport infrastructure as a mobility provider and public space as an urban amenity" [32].

Green routes now connect museums, cultural expression areas, and public art elements, demonstrating the transition from industry-driven growth to wellbeing-driven growth $[33,34]$. Furthermore, the fact that a series of cultural events takes place on a regular basis in the area [33,35] strengthens the identity of the site as a cultural node. It is noteworthy that just 15 months after the redevelopment, the park attracted approximately 90,000 visitors on a daily basis. The number of visitors is now estimated to be more than 20 million visitors [30,36], a large part of which are foreigners [36]. The positive impact on the economy is also reflected through the reallocation of companies near the area. During the implementation phase only, the number of businesses increased by $3.5 \%$ and the number of workers also increased by $0.8 \%$.

The growing interest in seeking a business location in the regenerated area has led to an increase in land values, which at times reached $50 \%$ of the initial price $[37,38]$. According to Byrne $(2017$, quoted in [38]), the benefits from land purchases only will yield billions of dollars of returns that will exceed 
the initial investment, which amounted to USD 367 million, according to the United Nations Human Settlements Programme (UN HABITAT) [39]. In addition to the purely economic effects, the overall impact of the project is multiplied by the fact that the social benefits are estimated at USD 3.5 million, according to the UN HABITAT [38].

Thus, it is clear that the intervention, which aimed, initially, at improving this downgraded region [40], environmental protection [28,41], as well as the promotion of sustainable mobility and transport safety [40], has become an "advanced culture-driven design project" [42], which has contributed to a more thorough development in the wider region and Seoul in general. Yoon [40] notes that the project is part of a broader vision of the authorities to transform the appearance of massive industrialization into a "cultural metropolis", which manages to combine the historical past with today's urban culture, while at the same time increasing socialization and stimulating the local economy.

A second case study is the redevelopment of New York's High Line. According to Ascher and Uffer [43], this is one of the most successful urban regeneration projects involving the re-use of an overhead rail line 1.6 miles long in Westside Manhattan [44], which was abandoned in the 1980s [45]. The area around the High Line mainly housed industrial buildings. After the regeneration of the line to an elevated park, about 350 galleries and other related businesses [46] were added. These were transferred in the 1990s from Soho to Chelsea Area [46,47], due to the low rents in the area, and created clusters of galleries mainly in the area between the 10th and the 11th Avenues, as well as between 20th and 27th Streets.

Unlike the Cheong-Gye-Cheon case, the area already had a cultural identity that was enhanced by art and culture landmarks, such as the Chelsea Studios, Pike's Opera House, and the Rubin Museum of Art [47]. High Line's intervention has strengthened the current cultural dynamism [46], as the site was transformed into a cultural hub and the High Line into a public corridor connecting recreational complexes and museums [48], new galleries, and art and trade venues, while newly-established extensions of existing cultural buildings are planned, e.g., the Whitney Museum which is expanding to host an exhibition space, a theater, and a restaurant [49]. The enhancement of the cultural cluster was one of the project's objectives along with the preservation of existing industrial architecture buildings (David, 2002, quoted in [48]). At the same time, sustainable mobility enhancement was achieved by promoting pedestrians' and cyclists' movement through a public participation process that decisively influenced public space management to the benefit of people [49].

The importance of the trail's regeneration is also recognized by Foster [50], who, accessing the spatial aspects of the project, underlines the importance of it as a crucial link between the two different areas of Manhattan, namely Lower Manhattan, which houses the financial and business center of New York; and Chelsea, which is the "creative field" of the city where creative industry (architecture, applied design, advertising) is booming.

The above presented projects (Figure 1) are just two of the very many cases where sustainable mobility has served either as a means of development or as a catalyst to the enhancement of the region's history, tendency, and past physiognomy. Although concerns and criticisms have been made regarding the increase of land values and the gentrification of the areas [30,61-63], the socio-economic revitalization of downgraded urban sections through strategic cultural enhancement and sustainable mobility is obvious. Hence, such examples are often used as good practices for the promotion of urban development and sustainability [49]. These two objectives are evident in a series of Greek projects, so the transferability of practices is very useful for areas with similar or related characteristics [64]. This paper incorporates such practices into a mixed strategy for the promotion of sustainable mobility and the development of culture-led corridors in Athens, in order for the synergy between the two sectors to be confirmed. The expected results and outcomes should be taken into account when assessing the planning proposal. A guide of recommendations that expands the current knowledge is derived from the projects presented above. Besides, the case study that is presented in Section 3 is a pioneering one as it attempts to develop a cultural axis, which is promoted by the Spatial Plan of the 
Athens Metropolitan Area, through the implementation of sustainable mobility planning, which is the top policy priority for the municipality of Athens.

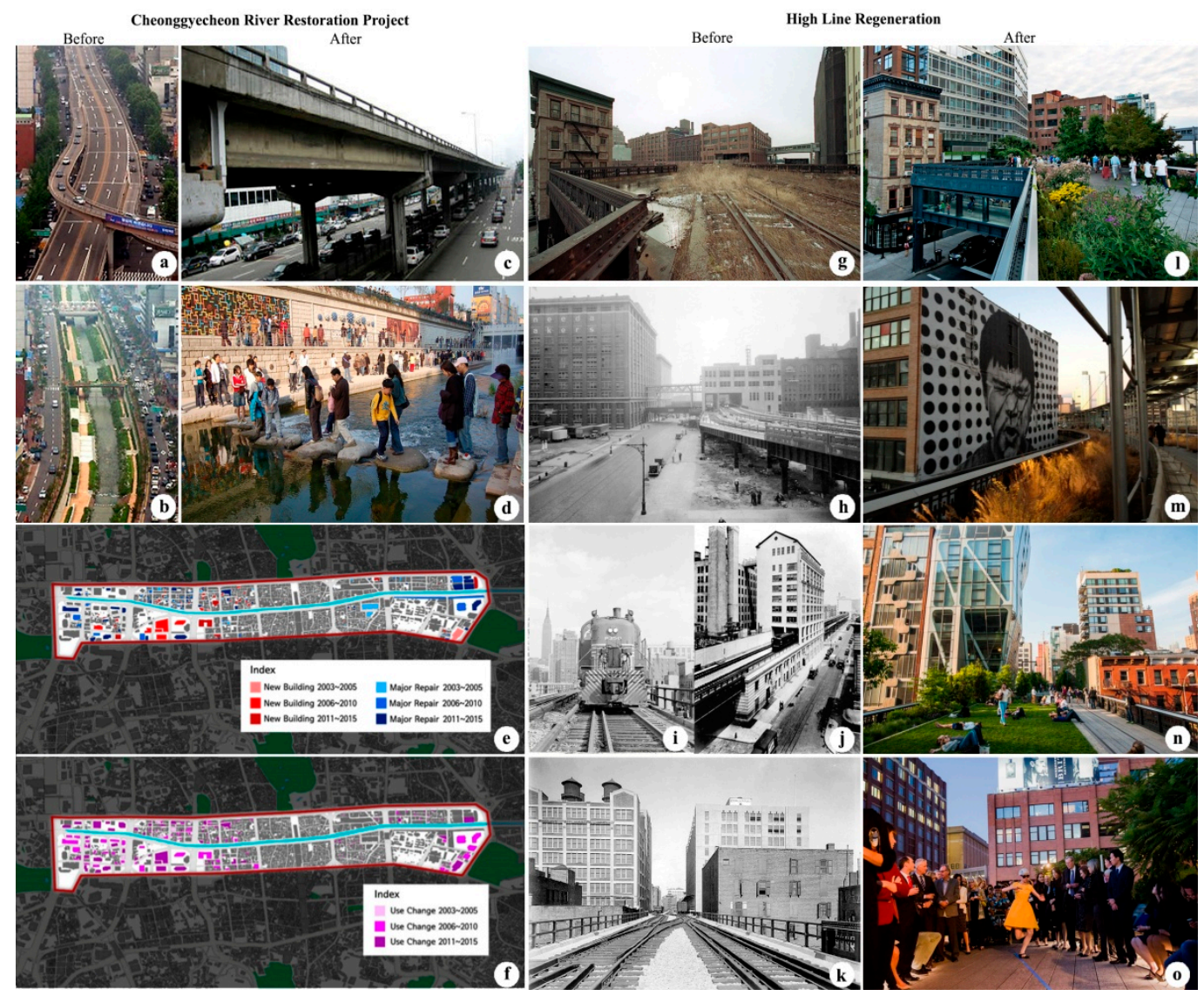

Figure 1. (a-d) Before and after gallery for the Cheonggyecheon [51-53]; (e,f) effect of the regeneration on land use and new construction projects [30]; (g-o) before and after gallery for High Line Renewal Projects [54-60].

\section{Case Study Research}

\subsection{The Case Study Area}

In recent years, there is an apparent tendency to transform the image of Greek cities. This observation is related to the economic recession that led a number of business sectors to shrink or even vanish, reduced incomes, and to modifications of recreational culture. At the same time, the great influx of refugees and migrants redefined the social geography of Greek cities-mainly of Athens-resulting in the formation of a cultural mosaic consisting of different needs that had to be satisfied in various parts of the public space. The incorporation of EU principles and directions for transforming cities into "economic cores" in the Greek policy framework [17], and their transition into "compact" zones [65], are further critical parameters for Greek cities' reorganization.

These directions have been expressed through the promotion of SUMPs, which are becoming increasingly popular in Greece as more and more cities are interested in promoting walking, cycling, public and shared transport, and placing restrictions on the current car-centric development.

Athens is considered an ideal case study since there is a growing public interest for the reformation of public spaces in its historic center and the reclaiming of streets from motorized traffic. This recent interest for the reallocation of the streetscape in favor of more sustainable means of transport in high streets (e.g., Panepistimiou Street) highlights the need for a robust reconsideration of the relationship between the form and function of the road, as in the above presented case studies. Such road axes are 
Patision Avenue, Acharnon Avenue, Piraeos Avenue, Vasileos Konstantinou Avenue, Kallirois Street, and Syggrou Avenue The latter three (Vasileos Konstantinou Avenue, Kallirois Street, and Syngrou Avenue) form a historical axis in which Ardittu Street is interposed. Along this axis are cultural activity buildings (see Section 3.3) and large hotels, similar to the case of High Line in the pre-rehabilitation period, forming a cultural corridor that does not have a clear identity, consistency, and unity.

\subsection{Methodology}

The focus of this research is on proposing a plan that establishes a cultural axis between Faliro and the center of Athens by implementing sustainable mobility policies. The proposed plan is not confined to physical planning, but also implements the use of smart applications, intelligent transportation systems (ITS), and citizens' participation in order to embed in this plan aspects of contemporary living that allow an effective physical layout of space [66], but also promote aspects of community building and engagement.

The reason for using the case study tool is to holistically study an issue [67] within its real-life context (empirically) [68]. Through an investigation of this area, a large number of features (land uses, height of buildings, traffic information, and policies) are gathered and analyzed, so that a complex issue like cultural planning can be investigated [69]. The findings derived by this case study research may be conceptualized in terms of the provision of procuratorial experience, as a basis for "naturalistic generalization" [70]. In that way, it is possible to propose models integrating transport planning with land use planning [71]. Through such models, sustainable mobility could be applied in urban areas [72-74].

Roughly speaking, the methodological approach in the specific case study context attempts to gain insight into the existing situation, formulate alternative proposals for redesigning the study area, evaluate them, and draw conclusions. More specifically, the steps followed comprise:

- Analysis of the current state: At this stage, the analysis aims at shedding light on the: (a) Geometric and functional characteristics of the examined road axis; and (b) the land uses and other urban features in a $150 \mathrm{~m}$ zone, on either side of the axis. Field research was carried out in 2017. At first, the research team focused on recording the current geometric characteristics of this complex and vital cultural axis of Athens and developed several cross sections. Crossings and public transport stations were also identified. Secondly, land uses were recorded, taking into consideration the ground and upper floors of the built environment, as well as the architectural features for buildings within the $150 \mathrm{~m}$ zone. In both cases, photographic documentation was also used to capture the urban and social characteristics along the axis [75].

In the analysis stage, the contribution of crowdsourcing data collection techniques [76] (e.g., Google Maps, Open Street Maps) was very critical for the correction of the background, collection of land use data, and recording of urban equipment and traffic congestion, similar to many relevant surveys carried out in the Athens metropolitan area [75,77,78]. The mapping of the data [54] and the tabulation [79] contributed to the understanding and visualization of the data collected.

Finally, at this stage, the existing policy documents were studied. Through this review, proposed planning interventions were clarified and thus, development strategies wereidentified.

- Having assessed the most critical issues in the study area at hand and the suitable practices identified by the two case studies in Seoul and New York that could eventually be transferred to the study region, alternative plan proposals were drafted. More specifically, three alternative scenarios were structured, which were diversified on the basis of the extent of interventions introduced by them and their cost (zero, conservative, and visionary). The focus of all three scenarios was on the promotion of sustainable mobility and ITS in order for the cultural character of the area to be enhanced. The reason why those issues formed the basis of the scenarios' evaluation was related to the character of the project as well as with the suggestions derived by the planning policy documents. 
- The proposed scenarios were evaluated by use of multicriteria analysis in order for a decision to be made as to the most relevant one, taking into consideration specific evaluation criteria properly rated as to their importance (criteria weights) [80]. Although the quantification of data was not a priority and qualitative data may be treated as superior, in the context of multicriteria analysis, quantification was also attempted.

\subsection{Study of the Current State}

The examined cultural axis consists of the Syngrou Avenue, Kallirois Street, Ardittou Street, and Vasileos Konstantinos Avenue. Located close to the municipal borders of Paleo Faliro, Kallithea, and Nea Smyrni, it crosses the western part of the municipality of Athens. The axis is not linear but forms a rather curved alignment (Figure 2), due to the fact that part of its delineation was engraved on the river Ilissos, which was covered in rubble in the 1950s to 1960s period (Belavilas, 2019, quoted in [81]). On both sides, high-rise buildings are prevailing (5 to 7 story buildings), with the exception of Ardittou Street, which accommodates the lowest structures. Most buildings are visually imposing, representing particular architectural forms of relative historic periods, and motivating the visitor to observe, even partially, the history of the Athenian architecture and its evolution along space and time in the city. However, most of the axis is dominated by the aesthetics of Modernism, since many neoclassical houses and refugee structures have given way to multi-dwelling houses developed through the land-for-apartment exchange system (contractual consideration), which mostly are in a bad condition or serve poor aesthetics.

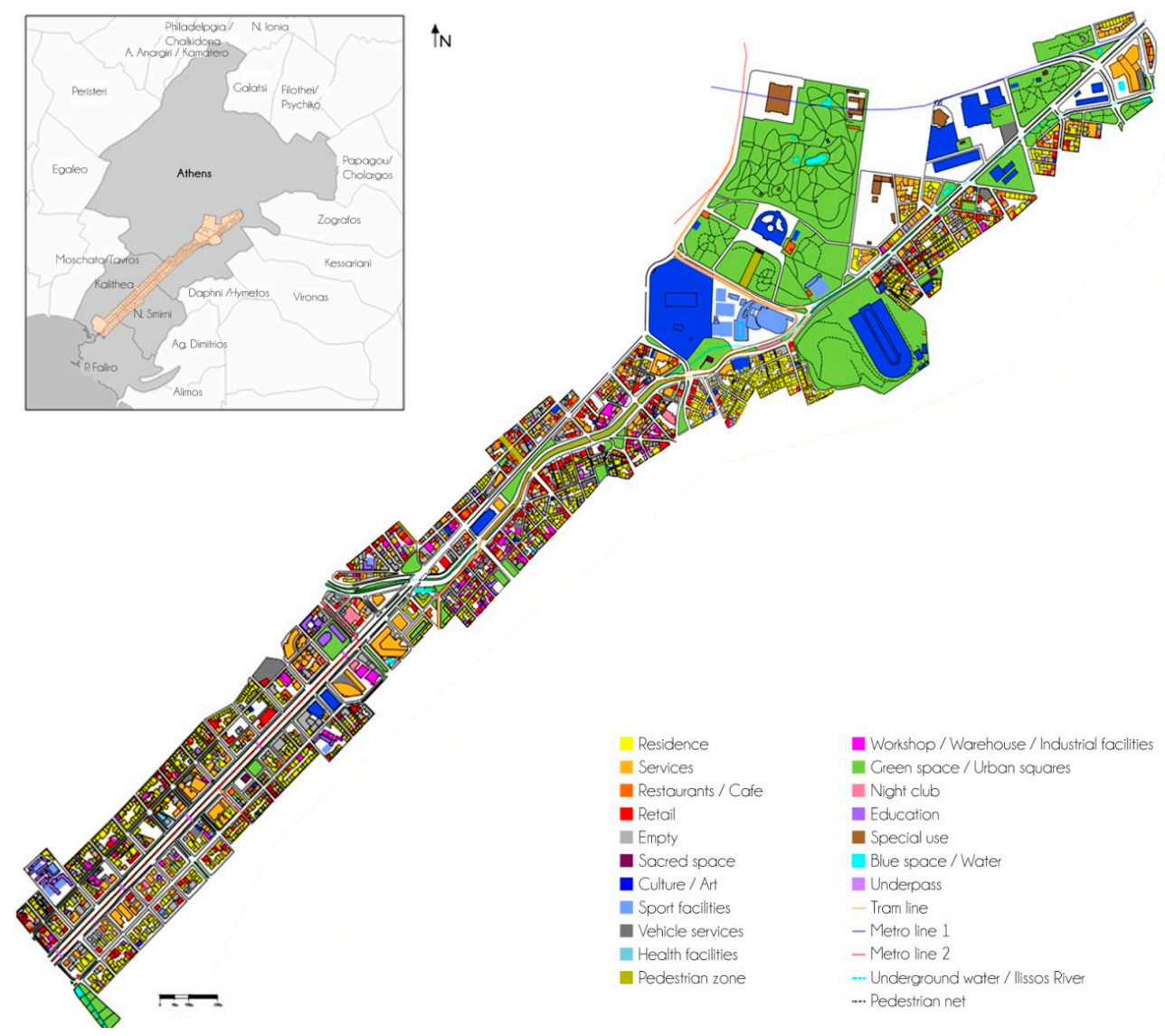

Figure 2. Land use map (ground floor use) of the case study area.

Regarding land uses, a mosaic of uses is depicted on both sides of the axis, as reflected in Figure 2. Vasileos Konstantinos Avenue accommodates several embassies, corporations, and offices, while retail stores are completely absent. Ardittou Street is dominated by housing and services. Tourist 
facilities, hotel units, cafes, and restaurants, as well as offices and services are located on Kallirois Street. Ultimately, Syngrou Avenue is characterized by the largest variety of uses, such as hotels, health facilities, car shops, services, restaurants, cafes, night clubs, brothels, and derelict buildings. It is characteristic that Syngrou Avenue is the road that is experiencing the biggest change in its character, since several hotel brand names have invested in the vicinity of this avenue [82] along with healthcare units. However, the observed pattern incorporates fewer empty spaces close to the seafront.

One of the key land uses in the area relates to culture-led facilities. More specifically the area hosts the National Gallery; four museums; the National Research Center; the Zappeion Palace; the Center for Literature and Arts; the Eugenides Foundation; the Stavros Niarchos Cultural Center (including the National Library and the National Opera); five theaters and cinemas; an academic institution; archaeological sites, such as the Adrian's Gymnasium; a part of the Ancient Walls; the Temple of the Olympian Zeus; and the Kallimarmaro Stadium (Figure 3). Along the axis, there are three parks and the National Garden, while the First Cemetery of Athens is nearby, in which there are important sculptures of Greek artists, the Presidential Palace, Maximo's Mansion, and other important museums and art galleries.

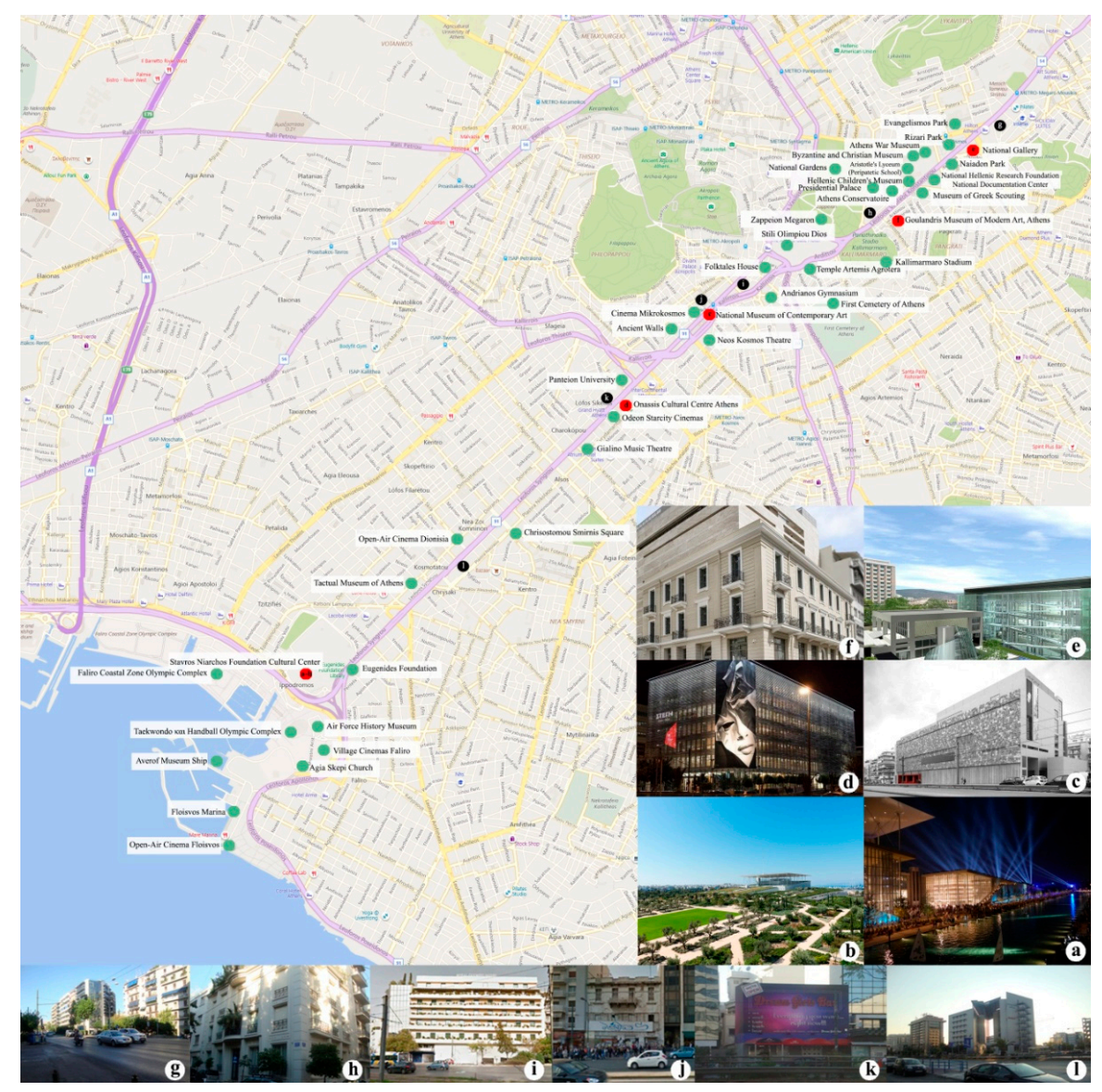

Figure 3. Cultural landmarks across the study area; (a,c-f) five important landmarks [83-87]; (b) Stavros Niarchos Foundation Cultural Center Park [88]; (g-l) architectural styles of the study area.

The above cultural spaces provide a wide range of cultural activities. However, the region is not identified as such for a number of reasons. The most important of them are:

- There is a lack of proper management and coordination of existing cultural infrastructure/ landmarks as a whole. Also, efforts to host cultural events or coordinated action to inform visitors about cultural activities in the area (e.g., museums or theaters) are missing. There is also currently 
no concern for a coherent mapping of the aforementioned landmarks as parts of a culturally vibrant axis or for branding of the place as such in a systematic way.

- Urban plans of neighborhood municipalities do not grasp or take steps to address the cultural prospects of the axis. Each municipality plan perceives this axis as a "border", i.e., an obstacle and not an opportunity. Although, in the Spatial Plan of the Athens Metropolitan Area, a provision for the enhancement of the axis as a cultural route is stated [18].

- Moreover, the existence of derelict buildings and several nightclubs, combined with the documented shadow economy activities, create a sense of insecurity for all road users during the late evening hours. The new national policy for upgrading all municipal plans stands as a great opportunity for the area. Future planning should identify land use conflicts in order to mitigate them.

- The poor quality of the public space and the fragmentation of existing free spaces affects the overall recognition and operation of the area as a cultural route. Many parks are neither related nor connected to each other. Urban furniture is worn out, sculptures are vandalized, and inadequate lighting welcomes delinquent groups. Public spaces do not coexist with cultural facilities. The National Gallery and the National Museum of Contemporary Art are known for their absence of provision for a public reception area and for their inability to host outdoor events.

- The whole road axis is not considered a pedestrian-friendly one. Table 1 summarizes the individual characteristics of each road section. Findings show that it is a highway road link with intense traffic volume at all times. Sidewalks are narrow and below the legal standards [89]. In relation to the drive lane width, it is worth mentioning that sidewalks occupy no more than $16 \%$ of the overall section. Very few crosswalks and street obstacles prove further that the axis operates exclusively as a car traffic channel and also as a barrier, according to the Lynch [90] approach, thus resulting in a functional separation of the areas. Due to the high vehicle speeds and the lack of exclusive bicycle infrastructure, the axis is also unfriendly for cyclists.

Table 1. Road characteristics of the study area.

\begin{tabular}{ccccc}
\hline Street/Avenue & Syngrou Avenue & Kallirois Street & Ardittou Street & $\begin{array}{c}\text { V. Konstantinos } \\
\text { Avenue }\end{array}$ \\
\hline Length $(\mathrm{km})$ & 5 & 1.2 & 0.5 & 1.3 \\
Width (m) & $65-70$ & $40-53$ & $35-38$ & $30-40$ \\
Lanes/Direction & $4-5$ (extra 2) & 3 & 2 & 2 \\
Bus lanes/Direction & 0 & 0 & Yes & No \\
Tram Lane & No & Yes & Yes & Yes \\
Traffic Island & Yes & $1.9-5.2$ & $2-3.4$ & $2.5-5.0$ \\
Sidewalks' width (m.) & 9 underground & 5 (Max: every 300 m.) & 3 (Not a specific pattern) & 12 (Max: every 200 m.) \\
Pedestrian Crossings & (every 500 m.) & & &
\end{tabular}

The presence of public transport accounts to the positive elements in the area. There are four trolley and nine bus lines linking the area to various parts of Athens. There is also a tram connection-crossing a part of this area-and a metro line that connects the area to several places in the Athenian conurbation. It should be underlined that since October 2018, the tram line between Syntagma and Neos Kosmos has been permanently out of order due to soil erosion. This issue opens another parameter and indicates that there is still room for further improvement of public transport along the axis, contributing to better connectivity of the historic center with significant landmarks, such as the Stavros Niarchos Cultural Center [91]. It is important to note that, according to the Regulatory Plan of Athens [18], bicycles are proposed as another means of transport linking the Athenian center with the Faliro bay. New cycling infrastructure is planned to be developed across Syngrou Avenue, which consists of a big part of the study area. This intervention would be accompanied by pedestrianizing axes where cultural activities are located in [18]. Both of those interventions are in agreement with the Strategic 
Plan for Transportation and Sustainable Mobility in Athens [92] and the Operational Program of the Municipality of Athens (2015-2019) [93].

\subsection{Proposals}

Considering the issues raised from the analysis of the current state of the area of concern and having as a main goal the integration of cultural facilities-mainly the five most important ones (Figure 3) - and their designation by use of sustainable mobility strategies, targeting the improvement of accessibility, and thus the attractiveness of the area and the promotion of its cultural assets and activities, three hierarchical scenarios were formulated:

- Do nothing scenario: This considers the current austerity policies and proposes no intervention in transportation and urban planning terms. It attempts solely to assist anyone commuting in the area as a pedestrian or a cyclist, providing alternative routes located in parallel roads with more relevant geometric features and less traffic, such as the Doiranis and Plastira Street. Information on these routes (Figure 4) can be communicated to citizens through information signs in front of points of interest, such as cultural landmarks. At the same time, information regarding the closest public transport station and links to all cultural sites are proposed. In a more refined version of this scenario, a dedicated website of this area is created, which provides information on commuting options and cultural landmarks, while these data can also be uploaded to existing information portals.

It is worth noting that although no redevelopment within those roads is necessary, it is possible and desirable to implement design interventions on those road segments in the context of the SUMPs for the municipalities of Kallithea (SUMP is completed) and Athens (SUMP will be forthcoming). In fact, it is believed that such interventions would be scheduled as existing policy documents (i.e., [92,93]), suggesting specific redevelopment works of the study area. The absence of an intermediate policy plan can contribute to an undesirable result for the study area. That means that it may not be totally recognizable as a cultural cluster.

- Conservative scenario: This scenario focuses on the implementation of a series of interventions that include the deployment of walking and cycling pathways alongside public transport routes. In this context, widening of the sidewalks along the whole axis is predicted, with a minimum width of $2.5 \mathrm{~m}$, in order to ensure the minimum unobscured pedestrian corridor width (Figure 5). Bike lanes along Kallirois Street and Syngrou Avenue are also incorporated in this scenario. Ardittou Street and Vasileos Konstantinos Avenue are turned into cycle streets and in parts of them cyclists move along an exclusively shared bus-bike lane. In that way, safety for bikers is increased. Driving lanes are reduced to one per direction in Syngrou Avenue in order to leave aside exclusive bus lanes. Service roads also face a similar road change to include bike lanes and wider sidewalks. "Smart boards" are to be installed around the study area in order to provide information about nearby cultural landmarks and recreational facilities and events along the axis.

Such a proposal is in agreement with the existing planning policy documents. However, in order to be implemented, a solution should be found concerning the function of the tram in the study area. As it was mentioned above, the tram line between Syntagma and Neos Kosmos is permanently out of order (from October 2018). That means that an additional cost is required in order for soil erosion to be effectively addressed.

- Visionary scenario-progressive: This scenario imposes radical and more visionary nature interventions that result in the modification of traffic flows and priorities, while they significantly increase sustainable mobility infrastructures. This scenario is in alignment with the proposal from Anaplasi Athinas S.A. (the "Regeneration of Athens") that has recently come to the forefront as a means for Ilissos' revelation and the creation of a linear park [81], which will unite half of the 
cultural landmarks in the studied cultural axis (Figure 6). It is crucial that such a plan is also supported by the existing problem concerning the function of the tram line. By appropriating this idea, the high cost of the repair works is eliminated while the soil erosion problem is finally solved by promoting an environmental friendly proposal.

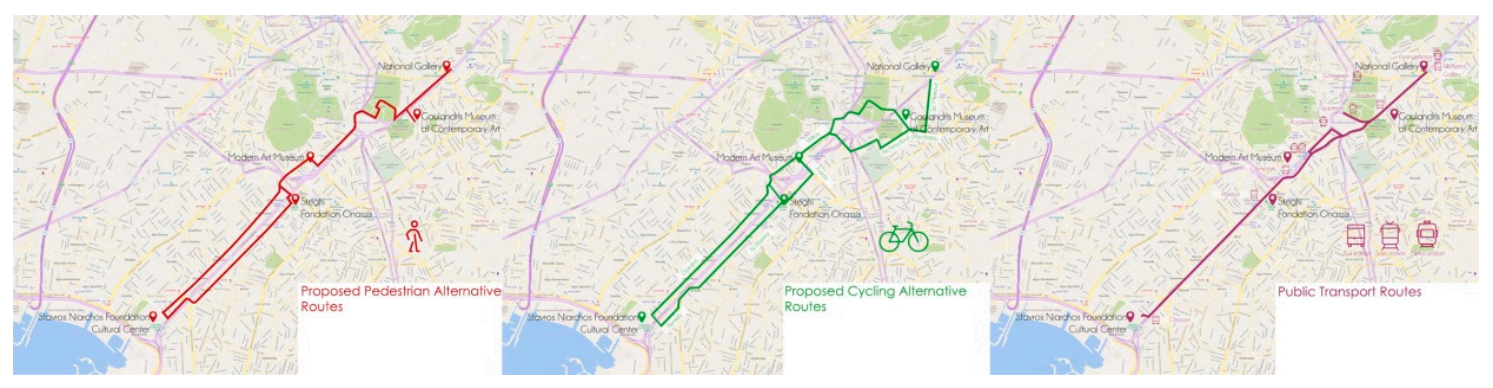

Figure 4. Do nothing scenario maps.
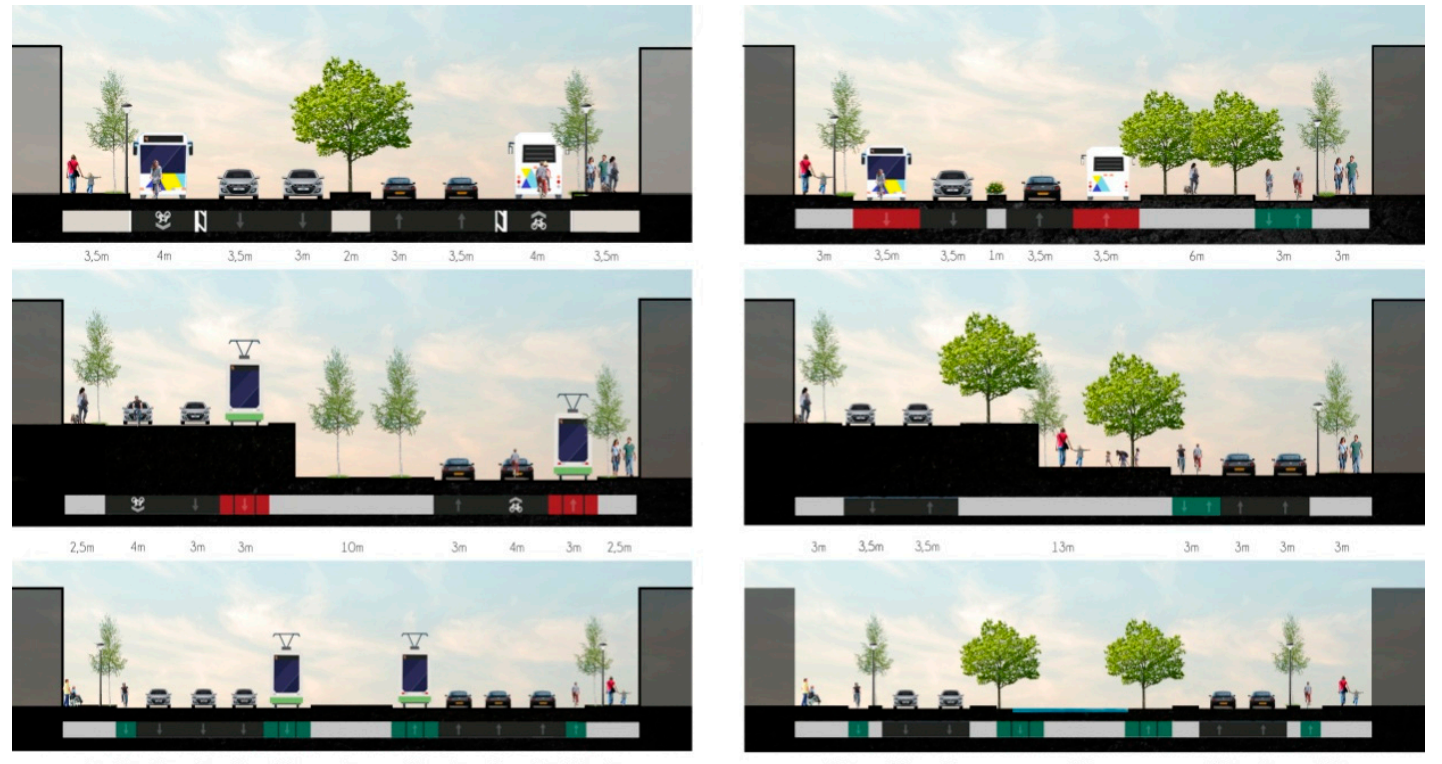

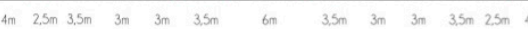
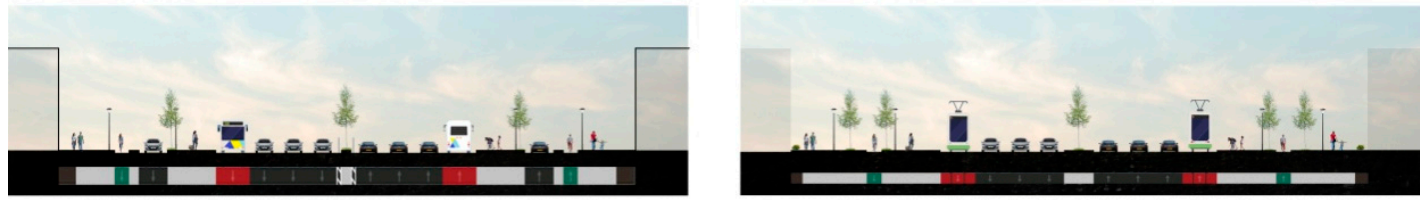

$\mathbf{a}$

b

Figure 5. (a) Proposed road configuration-conservative scenario; (b) proposed road configurationvisionary scenario. 


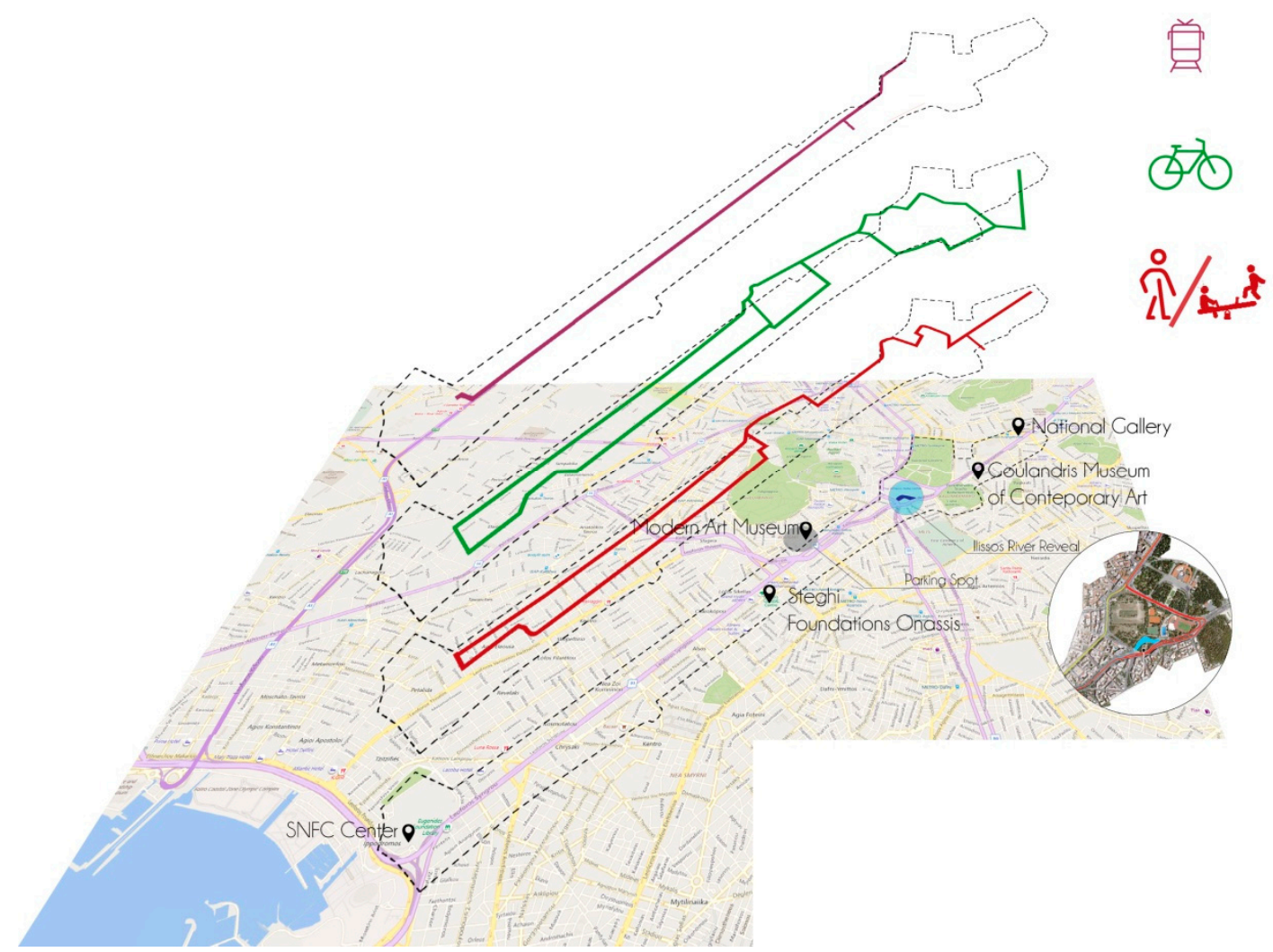

Figure 6. Visionary scenario conceptual map. The small figure on the left-hand side depicts the proposal for the Ilisos river restoration [81].

Within this scenario, the bed of Ilissos river between the National Museum of Contemporary Art and Agia Fotini is proposed to be revealed, following the paradigm of Seoul, while the tram line is relocated to Syngrou Avenue (Figure 6). This intervention creates a pedestrian-friendly $17 \mathrm{~m}$ wide zone in Kallirois Street, which is used to support the elevation of the river bed. Traffic circulation is adjusted to a narrower road, serving two lanes per direction, while the remaining area is reconfigured to serve as a green pedestrian path. This path can further follow the Vasileos Konstantinos delineation, with its traffic lanes rearranged to accommodate exclusive bus lanes and bike lanes (one per direction). The scenario predicts a complete reconfiguration of the two service roads in Syngrou Avenue in order to accommodate pedestrians, cyclists, and greenery. The presence of well accessed and configured public spaces near cultural landmarks is particularly important for their ability to support both outdoor and indoor events, allowing them to thrive among residents and visitors. Such spaces are also located near the study area and thus it is possible and desirable to extend the proposed green pedestrian paths into the neighborhoods. In that way, the emerging cultural district can be better integrated into the urban context of Athens. This policy is in line with the Spatial Plan of the Athens Metropolitan Area [18] as a green spaces network is proposed, as well as the other policy plans. It is also crucial that through this proposal another benefit is gained: The green traffic ring in Athens is expected to be more operational due to the fact that the aim of the visionary scenario proposal is to reduce the circulation of private vehicles in the city center and thus to reduce the levels of pollution and improve the quality of citizens' lives. Indeed, such a proposal can enhance the value of the ring measure that has been circumvented since most families have a second car, while car-friendly infrastructure and inactive controls lead most Athenians to the center. Contrary to the previous scenario, this scenario envisages the tramline formation, appropriately addressing the issues and offering a new perspective to the overall Athenian conurbation and public transport [94].

The design interventions are complemented by a series of "smart interventions" that go beyond the boundaries of the city organization and aim to ease circulation and attract further visitors with 
cultural interests in the area [66]. These complementary suggestions are important, representing the digital aspects of a spatial unity that aspires to become a smart region (Komninos, 2006, quoted in [95]). These interventions concern:

(a) The development of a smart parking system for informing drivers via electronic variable message signs and smartphones about the available parking spaces, reducing the time needed to find a parking space, improving traffic and environmental conditions, and increasing road safety levels ([96]).

(b) Installation in the area of smart lighting connected to traffic counters, which adapt their operation to further promote walkability. Bicycle traffic lights can further enhance bike circulation. Moreover, flashing Light-Emitting Diodes (LED) strips complement the safety aspects of pedestrians.

(c) Sustainable mobility in the overall area of the cultural axis area is also promoted through the development of a smart bicycle and e-scooter system for the enhancement of small scale mobility. This action can be implemented either with the cooperation of all neighboring municipalities or by a potential managerial body, who can handle all relevant activities within the cultural axis area.

(d) The placement of "smart boards" is incorporated in this scenario in order to inform the public about all activities in the overall area of the cultural axis.

(e) A network of Wi-Fi nodes is also deployed along the axis, which will allow the area to be identified as a broadband environment, supporting various e-services and enhancing urban intelligence [97].

(f) A smart city application that rewards people for sustainable commuting choices in daily travel. Commuters who use means of public transport, walk, or bike earn points. In exchange, they can participate in challenges and accumulate points redeemable for gifts and discounts. Most of the rewards could be associated with cultural activities in the emerging cultural axis, such as a free admission to a museum or a cultural event. Moreover, through such an application, ticket packages can be developed. Such ticket packages can provide access to the Athens public transport system along with several deals (discounted admission) on some museums in and around the emerging cultural axis.

The visionary scenario does not include any forecasts for smart stops, since the local bus regulating authority is already implementing telematics and other Information Technology System (ITS) services. All scenarios were evaluated through the use of multicriteria analysis. In particular, the regime method was implemented using Definite software, in order to identify which scenario best promotes the goal of this research, i.e., the question of linking cultural landmarks with sustainable mobility strategies. The evaluation criteria were formed taking into consideration the features of an ideal and desirable urban environment and the capacities of the existing one. The criteria used for the evaluation of scenarios were as follows;

- Promotion of sustainable mobility: It refers to the performance of scenarios as to the promotion of alternative means of transportation (walking, cycling, public transport). A qualitative scale $(-/+)$ was used for assessing scenarios' performance with respect to this criterion. The do nothing scenario retains the problems, discouraging the promotion of sustainable mobility; it gets a negative score (-). The conservative scenario creates certain opportunities and it gets a positive, yet contained score $(+)$. The visionary scenario reforms the transportation network, pushing people to try alternative transportation habits; the scores is strongly positive (+3). Upgrade of the environment: It is related to the impact of the proposed interventions on the overall urban environment of the area. A qualitative scale was also used for this criterion. The do nothing scenario will degrade the urban fabric; it gets a negative score (-). This negative score is also supported by the fact that existing planning policy documents suggest specific interventions that might not be implemented in the case that a spatially focused plan does not include them. The conservative scenario gets a positive, yet contained score $(+)$. The visionary scenario greatly enhances the urban space; the scores is strongly positive $(+3)$. The positive score is related to the direct correlation between this proposal and the existing planning policy. 
- Overall cost of interventions: Related to the costs involved in the implementation of the proposed scenarios. The do nothing scenario does not require significant funds so the score is 0 . The conservative scenario has many expenses and it gets a negative score $(-2.5)$. In those expenses, the cost for repairing the tram line function is also included. In fact, the cost of repair works is so high that there will be a possibility that the works may not be completed. In case that happens, the tram line will be interrupted from the Neos Kosmos to Syntagma stops and the provision of the Regulatory Plan of Athens that the tram line will be extended until Patisia is canceled. The visionary scenario demands great interventions, plantations, and other amenities; the score is strongly negative $(-3)$.

- Traffic service level: This is aimed at studying the impact of interventions on traffic flows and delays on the road axis. In this case, the interval quantitative scale was used. The do nothing scenario does not affect the vehicle space, so the score is 0 . The conservative scenario has a few vehicle lanes cut off and it gets a negative score of -1.5 . The visionary scenario instructs that some of the vehicle lanes must be removed; the score is -2 .

To determine the weights presented above, a ranking method was used. Through a cardinal scale that depicts the importance of the criteria from the most to least important, and the prioritization, as shown above, that latter got standardized. The cost and reduction of the traffic service level is not as important because of the belief that promoting sustainable mobility and upgrading the environment will decrease the need for car transportation and will increase investments. The qualitative scale was mostly used for the evaluation scores, since providing quantitative data is not possible or exceeds the point of this study. The qualitative scale was used only for the traffic service level to coarsely depict the loss of the car space.

Based on the priorities attached to all criteria (the first two criteria are also strongly suggested by the planning policy documents) that weigh their importance in the specific evaluation exercise, the visionary scenario seems to be the prevailing option (Table 2), rated first in the assessment of scenarios' performance. Figure 7 shows the results of the multicriteria analysis.

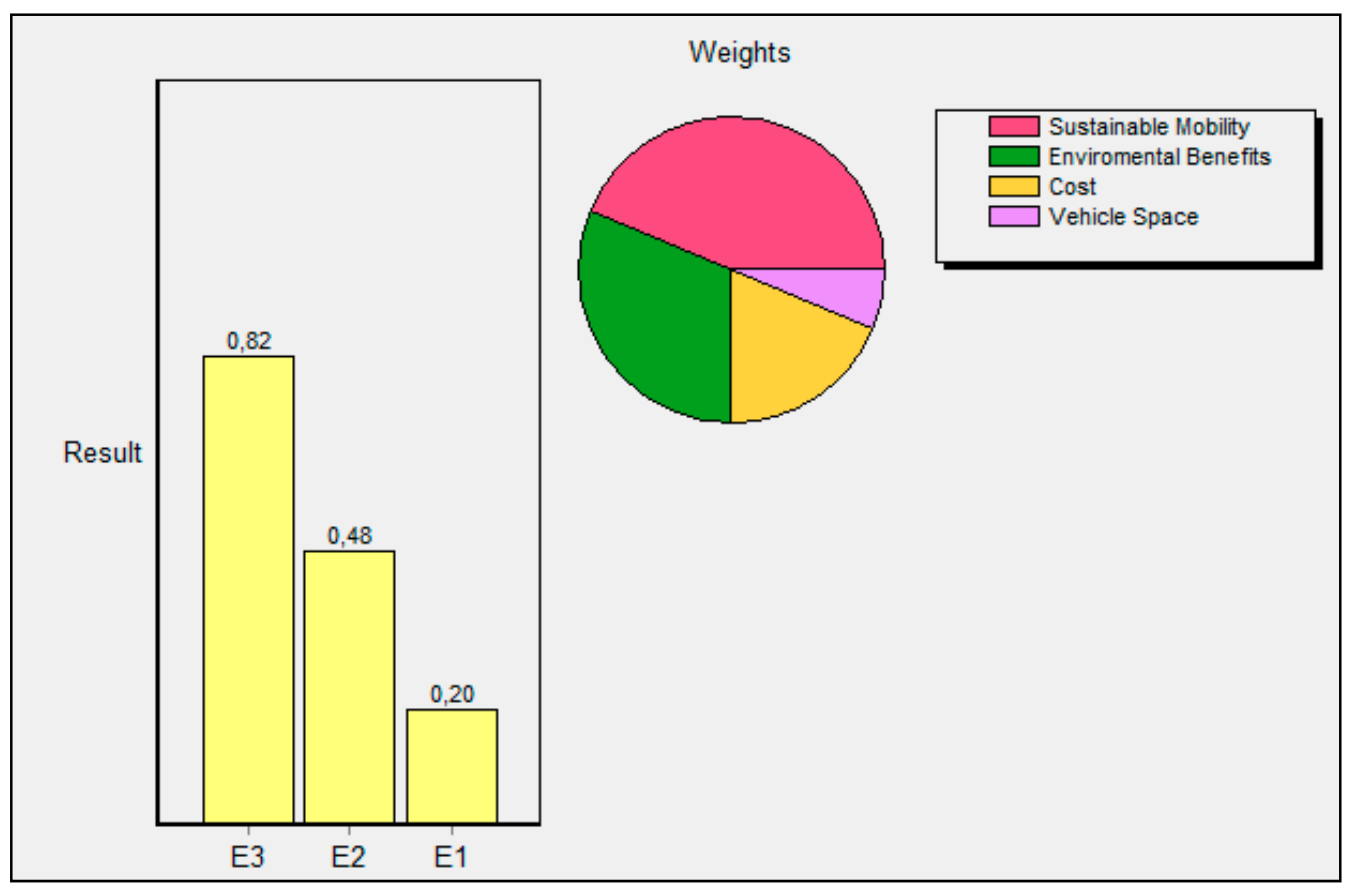

Figure 7. The results of the multicriteria analysis. 
Table 2. Scenario evaluation.

\begin{tabular}{cccc}
\hline & Do Nothing Scenario & Conservative Scenario & Visionary Scenario \\
\hline Promotion of sustainable mobility & -1 & +1 & +3 \\
Upgrade of the environment & -1 & +1 & +3 \\
Overall cost of interventions & 0 & -2.5 & -3 \\
Traffic service level & 0 & -1.5 & -2 \\
Total & -2 & -2 & +1 \\
\hline
\end{tabular}

\section{Discussion}

In the present article, the research focused on how the implementation of sustainable urban mobility plans (SUMPs) and overall sustainable mobility strategies can enhance cultural strategies and upgrade emerging cultural clusters, using as a case study a cultural corridor of the Athens metropolitan area that connects the seaside area with the city center. The studied axis, being a place where numerous cultural activities unfold, remains currently unexploited in cultural terms, with scattered and disconnected cultural assets, while it lacks a strategy for building and promoting a cultural branding identity. We took advantage of the relevant good practices implemented elsewhere, e.g., the case of Pittsburg cultural district (discussed in Section 2). Linkages of these two research fields and planning practices, i.e., cultural routes/development and SUMPs, are gaining more and more attention by Greek urban planners due to two main reasons, namely: (a) The emerging concept of sustainable mobility that is becoming very popular in decision makers' and citizens' minds, which is also the outcome of EU guidelines and the relative funding raised as well as the priorities of the national agenda for more sustainable and accessible cities; and (b) the economic recession, which has further downgraded and deregulated various urban spaces.

In light of the above aspects, the article aimed to highlight these issues in a specific case study area and render this area an important and easily and sustainably accessed cultural route, capable of broadening attractiveness and boosting investments, while creating a culturally upgraded environment for both tourists and residents. Planning of the cultural regeneration of the study area was based on a comprehensive analysis of the current situation, scenario development, and evaluation in order to support more knowledgeable decision-making.

The dominant element of the proposed plan is the revelation of Ilissos river as a key natural element of the past, taking into account experience-based results and good practices, such as the example of Seoul, where significant environmental benefits have been recorded, such as the increase of biodiversity, the reduction of the urban heat island effect, and the protection against flooding incidents in the city $[25,98,99]$. The heat island effect as well as flooding are facts Athens faces. [100,101]. The benefits, however, arising from the river restoration in Seoul also extend to sustainable mobility, since the revelation of the river was inextricably linked to the abolition of a major motorway. Alterations in commuting behaviors, a reduction of unnecessary car trips, and a decrease in car speeds are also noticeable outcomes of this intervention, while the number of metro passengers increased and traffic flow through the area improved [102]. More specifically, the restoration project has contributed to a $3.3 \%$ increase in subway ridership and a 15.1\% increase in bus ridership in Seoul between 2003 and 2008 [103]. In the case of the Athenian axis, the increase in the number of citizens using public transport is expected to be equally important, given the development of the new tramway infrastructure. The new tram line is expected to radically change the image of the city by reducing the car use and consequently altering citizens' commuting habits [104]. Tourists can also be attracted by the new infrastructure and spend more time visiting single cultural facilities. The Seoul paradigm witnessed a vast increase in the number of tourists since the beginning of the project, thus contributing to the inflow of capital and the development of new entrepreneurships, i.e., new businesses that had already begun to reallocate to the Cheonggyecheon area during the project planning stage [37,99].

The economic revitalization was also apparent in the case of New York's HighLine through cooperation between political, economic, and cultural actors [105]. The rail-to-trail conversion and the 
development of a linear park has strengthened the concentration of cultural and creative industries, which was also apparent through street art. Along the HighLine, a series of sport and artistic events take place throughout the year, which further enhances the character of the cultural axis. These events attract large audiences, which relate to a high concentration of commercial activities and residential development as a result of the overall regeneration [106]. However, the presence of people is a result of the space affordances $[73,79]$, and the design qualities that support or constrain behaviors and activities $[79,107,108]$.

The qualities that stand out in the case of the HighLine project include the development of pedestrian friendly corridors, the enhanced microclimate by green route implementations, the allocation of upgraded urban furniture in critical spots, and the presence of several viewpoints along the line. These qualities, combined with proper land use zoning and distribution of activities, make the space even more attractive to new visitors [54,109], and increase the sense of safety [110]. Considering the above, the provision of the Athenian redevelopment plan for a specific cultural axis is expected to attract more walking and cycling visitors and residents, targeting both commuting and leisure activities.

In fact, the presence of various means allows for intermodal transportation, which typically increases the number of users [111] and thus contributes to the extended presence of people during both day and night, making the area safer.

Gospodini [9] points out that such a project can attract investments and further develop cultural, creative, commercial, and recreational activities. Moreover, it can boost the rehabilitation of derelict buildings and attract creative clusters that are currently located near Pireos Avenue.

Aiming to address the research question, it is well documented that combined planning for the promotion of sustainable mobility and the development of cultural areas can show positive effects and complementarity, which is also the case for the studied project in Athens. Thus, it is believed that culture-led strategies can be incorporated in SUMP implementation, especially for cities that have a strong historical background.

\section{Conclusions}

This research paper focused on the upgrading of areas with particular interest (quarters), especially those located in historical and cultural cores. The strategy tested, i.e., the SUMPs, is a widespread urban planning practice, applied in several Greek cases during the last 15 years. Although it began as an autonomous urban and architectural regeneration planning endeavor, the introduction of SUMPs in the Greek planning perception and the good practices developed abroad have raised the importance of their integration into other types of urban planning exercises in order for successful mixed policies, targeting urban sustainability objectives, to emerge.

In order to investigate the added value of such a policy mix in the Greek context, the present study was carried out as an attempt to: Study good practices from areas that have already successfully tested such mixed policies; and formulate, based on this type of policy, an integrated approach for broadening the attractiveness of an emerging cultural axis in the Athens metropolitan area. The experience gained from the research conducted draws useful conclusions about the potential of the integration of SUMPs into cultural and regeneration planning in Greece. More specifically:

- The emergence and regeneration of cultural areas is a practice that can enhance the social and economic life of Greek cities, especially during this recession period. This can alter the character of regions or cities and even the citizens' culture. Long-term effects also include the strengthening of tourists' attraction in previously neglected downgraded zones, thus leading to their cultural and economic revitalization.

- Citizens' presence in public places is essential. Although Greece had a tradition regarding lively cities and vivid squares, contemporary lifestyle and consumerism have altered its physiognomy, thus breaking down the relationship between people and space. Austerity policies can be identified as an opportunity for re-inventing and further investing in public spaces as well as for shifting to alternative costless means of transport, which is at the heart of SUMPs. 
- The use of smart tools and intelligent transport systems (ITSs) can further attract visitors (residents and tourists) and extend their presence in the proposed culturally regenerated area, while also going hand in hand with sustainable urban mobility policies towards the establishment of synergies that improve urban qualities. Both can also steer the entrepreneurial attractiveness of the study area.

- Both research fields, i.e., cultural regeneration and SUMPs, have common goals and create positive developmental motivation wherever they are applied, as depicted by culturally regenerated areas around the world, which are commonly surrounded by pedestrian pathways and linked to neighboring centralities through public transport.

The last finding is the most important one. The reason is because it fills the gap found in the implementation of such policies in Greece. As was mentioned, no special reference to cultural strategies and synergies to related directions for sustainable mobility are defined in the current legislative framework for the implementation of SUMPs in Greece. Thus, planers may not take into consideration the links between such policies when a SUMP is going to be implemented. Those synergies are referred only to the Spatial Plan of the Athens Metropolitan Area that focuses only on the Attiki region and not on other cities for which there is an on-going or forthcoming SUMP. Through the formulation of a planning proposal for Athens and an ex-ante evaluation of this proposal, the links between cultural regeneration and sustainable mobility strategies were highlighted. They are set out in a guideline promoting a combined planning process:

- Both cultural regeneration and sustainable mobility policies have a common target: The operational and conceptual unification of city spaces. Exploring and understanding the desirable role and function of public spaces in a city can be investigated in two ways: The recording of land uses and activities that take place across the city/study area as well understanding people's needs (use of public transport, resting areas, playgrounds, etc.) that are expressed through specific behaviors. Thus, it seems necessary for urban planners to use not only conventional methods to analyze the existing situation of an area but also modern innovative tools.

- An innovative method was used in the case study presented above: Crowdsourcing. This technique is related to public engagement in order for data to be collected. In the case study examined above, the obtained data were related to the form and function of the study area and they were derived without any involvement of volunteers (Google maps and Open Street Map platforms). However, in case urban planners are interested in collecting additional quantitative (i.e., noise levels) or qualitative data (i.e., main problems or solutions proposed by users, interest in arts/culture, motives for using public transport), this technique could be useful in the primary data collection process.

- Applying good practices means learning from and through the experience of others, in Greece or abroad. It is a technique that has proven to reliably lead to a desired result concerning action plan preparation and an ex-ante evaluation of the proposed interventions. Indeed, through comparison with similar plans, a risk analysis as well as the outcome of such interventions both in mobility as well as cultural terms could be estimated.

- As far as the action plan is concerned, it should focus not only on the physical design of an area but also on its management. Taking into consideration that Greeks prefer to travel around cities by car, sustainable mobility interventions may not have a clearly positive impact with regard to social acceptance at the initial stage of their implementation. Thus, to encourage the use of public transportation, incentives may be offered to potential users. This paper developed such a mixed motivation: A reward system for citizens and tourists that use public transportation. Users of public transport were awarded free admissions to museums and cultural sites across the emerging cultural axis, by using a mobile application. This could be a typical example of an intensive method that can be used in order for sustainable mobility to be promoted and citizens and tourists to be attracted in cultural clusters. 
- Technology should be an important component of such a proposal. Only in that way is it possible for a reward policy to be applied. At the same time, when innovative installations are placed in an area, it is easily perceived as a special district.

- The key to a proposal evaluation and an optimal scenario choice is having in mind the common goal of the promotion of sustainable mobility and the development of a successful cultural district. Evaluations focused more on one direction should not be accepted. Dysfunctions may emerge in the near future.

Author Contributions: All authors have equally contributed to this article and have closely cooperated in writing, reviewing, and editing the text of the manuscript.

Funding: The authors received no specific funding for this work.

Conflicts of Interest: The authors declare no conflict of interest.

\section{References}

1. McGreal, S.; Adair, A.; Berry, J.; Deddis, B.; Hirst, S. Accessing private sector finance in urban regeneration: Investor and non-investor perspectives. J. Prop. Res. 2000, 17, 109-131. [CrossRef]

2. Davies, J. The governance of urban regeneration: A critiques of the "governing without government" thesis. Public Adm. 2002, 80, 301-322. [CrossRef]

3. Kyriakidis, C.; Siolas, A. Leisure and cultural clusters as a means of growth. The case study of the Commercial Triangle in Athens. In Proceedings of the 11th Tactical Scientific Conference ERSA-GR, Patras, Greece, 14-15 June 2013.

4. Nobre, E. Urban regeneration experiences in Brazil: Historical preservation, tourism development and gentrification in Salvador da Bahia. Urban Des. Int. 2002, 7, 109-124. [CrossRef]

5. Dabinett, G. Realizing regeneration benefits from urban infrastructure investment: Lessons from Sheffield in the 1990s. Town Plan. Rev. 1998, 69, 171-189. [CrossRef]

6. Plaza, B.; Haarich, S. Museums for urban regeneration? Exploring conditions for their effectiveness. J. Urban Regen. Renew. 2009, 2, 259-271.

7. Montgomery, J. Cultural quarters as mechanisms for urban regeneration. Part 1: Conceptualizing cultural quarters. Plan. Pract. Res. 2003, 18, 293-306. [CrossRef]

8. McCarthy, J. Regeneration of cultural quarters: Public art for lace image or place identity? J. Urban Des. 2006, 11, 243-262. [CrossRef]

9. Gospodini, A. Shaping, interpreting and classifying the new landscapes of the post-city. In The New Urban Landscapes and the GREEK City; Gospodini, A., Beriatos, E., Eds.; Kritiki Publishing: Athens, Greece, 2006; pp. 26-51.

10. Smith, M. Introduction. In Tourism, Culture and Regeneration; Smith, M., Ed.; CAB International: Oxfordshire/ Cambridge, UK, 2007.

11. Bianchini, F. Remaking European cities: The role of cultural policies. In Cultural Policy and Urban Regeneration. The West European Experience; Bianchini, F., Parkinson, M., Eds.; Manchester University Press: Manchester, UK, 1993; pp. 1-20.

12. Souliotis, N. Cultural strategies and urban regeneration in the historic centre of Athens: Local conditions and global trends. In Proceedings of the 2nd Pan-Hellenic Conference of Urban Planning and Regional Development, Volos, Greece, 24-27 September 2009.

13. Yelinek, A. Culture as a Tool for Urban Regeneration. 2009. Available online: http://www.jiis.org/.upload/p ublications/culture\%20and\%20urban\%20regeneration.pdf (accessed on 28 August 2011).

14. Gospodini, A. European cities in competition and the new uses of urban design. J. Urban Des. 2002, 1, 59-74. [CrossRef]

15. Martone, A.; Sepe, M. Creativity, urban regeneration and sustainability/The Bordeaux case study. J. Urban Regen. Renew. 2012, 5, 164-183.

16. Mommaas, H. Cultural clusters and the post-industrial city: Towards the remapping of urban cultural policy. Urban Stud. 2004, 41, 507-532. [CrossRef] 
17. Bakogiannis, E.; Kyriakidis, C.; Siti, M.; Koumparakis, G.; Athanasoglou, C. Identifying sustainable measures in medium-sized Greek cities. Urban. Inf. Spec. Issue 2018, 278, 8-12.

18. Act 4277/2014 (FEK -Official Gazette A' 156/1-8-2014). Available online: https://www.e-nomothesia.gr/kat-pe riballon/skhedia-poleon/n-4277-2014.html (accessed on 30 May 2019).

19. Act 4599/2019 (FEK -Official Gazette 40/A/4-3-2019). Available online: https://www.e-nomothesia.gr/kat-ay tokinita/adeies-odegeses/nomos-4599-2019-phek-40a-4-3-2019.html (accessed on 30 May 2019).

20. Evans, G. Hard-branding the cultural city from Prado to Parada. Int. J. Urban Reg. Res. 2003, 27, 417-440. [CrossRef]

21. Miles, S.; Paddison, R. Introduction: The rise and rise of culture-led urban regeneration. Urban Stud. 2005, 42, 833-839. [CrossRef]

22. Lin, C.Y.; Hsing, W.C. Culture-led urban regeneration and community mobilization: The case of the Taipei Bao-An Temple AREA, Taiwan. Urban Stud. 2009, 46, 1317-1342. [CrossRef]

23. Rodriguez, A.; Martinez, E. Restructuring cities. Miracles and mirages in urban revitalization in Bilbao. In The Globalized City. Economic Restructuring and Social Polarization in European Cities; Moulaert, F., Rodriguez, A., Swyngedouw, E., Eds.; Oxford University Press: New York, NY, USA, 2003.

24. Shin, J.H.; Lee, I.K. Cheong Gye Cheon restoration in Seoul, Korea. Proc. Inst. Civ. Eng. Civ. Eng. 2006, 159, 162-170. [CrossRef]

25. Park, K.D. Cheonggyecheon Restoration Project. In Proceedings of the JFES-WFEO Joint International Symposium on River Restoration, Hiroshima, Japan, 13 September 2007; pp. 9-20.

26. Lee, I.K. Cheong Gye Cheon Restoration Project. 2006. Available online: https://www.irbnet.de/daten/iconda /CIB7972.pdf (accessed on 23 March 2019).

27. Institute for Transportation and Development Policy and EMBARQ. The Life and Death of Urban Highways. 2012. Available online: https://3gozaa3xxbpb499ejp30lxc8-wpengine.netdna-ssl.com/wp-content/uploads/20 14/07/42.-LifeandDeathofUrbanHighways_031312.pdf (accessed on 22 March 2019).

28. Reig, I.B.; Roig, L.B.; Marcenac, V.; Lujan, N.S. Linear parks understood as vertebration instruments of the city. In Proceedings of the 24th ISUF International Conference: City and Territory in the Globalization Age, Valencia, Spain, 27-29 September 2017; pp. 983-993.

29. Kang, J. AR Teleport: Digitan Reconstruction of historical and cultural-heritage sites for mobile phones via movement-based interactions. Wirel. Pers. Commun. 2013, 70, 1443-1462. [CrossRef]

30. Ryu, C.; Kwon, Y. How do mega projects alter the city to be more sustainable? Spatial changes following the Seoul Cheonggyecheon restoration project in South Korea. Sustainability 2016, 8, 1178. [CrossRef]

31. Rukmana, D. Rapid urbanization and the need for sustainable transportation policies in Jakarta. IOP Conf. Ser. Earth Environ. Sci. 2018, 124, 12017-12025. [CrossRef]

32. Cervero, R. Urban reclamation and regeneration in Seoul, South Korea. In Physical Infrastructure Development: Balancing the Growth, Equity and Environmental Imperatives; Ascher, W., Krupp, C., Eds.; Palgrave Macmillan: New York, NY, USA, 2010; pp. 187-201.

33. Shin, J.; Park, H.; Seo, J.; Lee, J.; Park, H. Analysis of local and periodical transition in Cheong-Gye-Cheon to harmonize locality for urban green growth. J. Civ. Eng. 2014, 19, 2005-2016. [CrossRef]

34. Park, H.; Shin, J. Localities and Urban Green Growth: Half century's revitalization of Cheon-Gye-Cheon (CGC) in Seoul. Korea World Econ. 2017, 18, 167-203.

35. Khanal, P.; Gurung, A.; Chand, P.B. Road expansion and urban highways: Consequences outweigh benefits in Kathmadu. HIMALAYA J. Assoc. Nepal Himal. Stud. 2017, 37, 107-116.

36. Kriznik, B. Selling global Seoul: Competitive urban policy and symbolic reconstruction of cities. Rev. Za Sociol. 2011, 41, 291-313. [CrossRef]

37. Shafray, E.; Kim, S. A study of walkable spaces with natural elements for urban regeneration: A focus on cases in Seoul, South Korea. Sustainability 2017, 9, 587. [CrossRef]

38. Winifred, C.; Hamilton, T. Forward. In Just Green Enough. Urban Development and Environmental Certification; Winifred, C., Hamilton, T., Eds.; Routledge: Abingdon, UK; New York, NY, USA, 2017.

39. UN HABITAT. Urban Patterns for a Green Economy. Working with Nature; UN-HABITAT: Nairobi, Kenya, 2012.

40. Yoon, Y. Cheonggyecheon Restoration Project: The politics and implications of globalization and gentrification. Dartm. Undergrad. J. Politics Econ. World Aff. 2018, 1, 8.

41. Ipingbemi, O. Green transport for Nigerian cities. In Building Clean Cities in Nigeria; Wahab, B., Atebije, N., Yunusa, I., Eds.; NITP and TOPREC: Abuja, Nigeria, 2014. 
42. Lee, J.Y.; Anderson, C.D. The restored Cheonggyecheon and the quality of life in Seoul. J. Urban Technol. 2014, 20, 3-22. [CrossRef]

43. Ascher, K.; Uffer, S. The High Line Effect; Council on Tall Buildings; Urban Habitata: New York, NY, USA, 2015; Available online: http://global.ctbuh.org/resources/papers/download/2463-the-high-line-effect.pdf (accessed on 24 March 2019).

44. Porter, A.; Ashton, A. Highline Park. 2003. Available online: http://ashtonporter.com/all-projects/cultural/h ighline/ (accessed on 24 March 2019).

45. Aitani, K.; Sathaye, V.K. New York High Line as urban catalyst: Impact to neighborhood. In Proceedings of the 24th ISUF International Conference: City and Territory in the Globalization Age, Valencia, Spain, 27-29 September 2017; pp. 1665-1672.

46. Harrison, R. Transformation of Urban Public Space. Master's Thesis, University of Massachusetts Amherst, Massachusetts, MA, USA, 2012. Available online: https://scholarworks.umass.edu/cgi/viewcontent.cgi?artic le $=1972 \&$ context=theses (accessed on 22 March 2019).

47. Toni, A.; Abdollahi, S. Kilometro Zero Tower. 2014. Available online: https://www.politesi.polimi.it/bitstre am/10589/90444/1/2014_04_Toni_Abdollahi_01.pdf (accessed on 24 March 2019).

48. Mayer, P.; Saunders, M.J. Regenerating the core-Or is it periphery? Reclaiming waterfronts in US cities. In The Routledge Companion to Urban Regeneration; Leary, M., McCarthy, J., Eds.; Routledge: London, UK; New York, NY, USA, 2013; pp. 179-189.

49. Bakogiannis, E. Good Practices for Promoting Sustainable Urban Mobility, 1st ed.; Gregoris Publications: Athens, Greece, 2018.

50. Foster, J. Off Track, In Nature: Constructing ecology on old rail lines in Paris and New York. Nat. Cult. 2010, 5, 316-337. [CrossRef]

51. Anon. Cheonggyecheon Stream The Restoration Project. Available online: http://blogtalkwithejay.blogspot. com/2014/10/cheonggyecheon-stream-restoration.html (accessed on 29 March 2019).

52. Tran, C. Seoul/Cheonggyecheon, the Symbol of the Modernity. 2014. Available online: http://fac.arch.hku.hk/ asian-cities-research/seoul-cheonggyecheon-the-symbol-of-the-modernity/ (accessed on 29 March 2019).

53. Herwing, O. Go with the Flow. 2016. Available online: https://www.smart-magazine.com/restoring-cheongg yecheon-river/ (accessed on 29 March 2019).

54. The New York Times. Before and After Bloomberg. 2016. Available online: https://archive.nytimes.com/www.ny times.com/interactive/2013/08/18/nyregion/before-and-after-bloomberg.html (accessed on 29 March 2019).

55. Anon. Go for Walk and Discover the High Line in New York. 2018. Available online: https://www.new-york -city-travel-tips.com/go-walk-discover-high-line-new-york/ (accessed on 29 March 2019).

56. Wikipedia. High Line. 2019. Available online: https://en.wikipedia.org/wiki/High_Line (accessed on 29 March 2019).

57. Columbia University. High Line Construction. Available online: http://ccnmtl.columbia.edu/projects/caseconsort ium/casestudies/128/casestudy/www/layout/case_id_128_id_903.html (accessed on 29 March 2019).

58. Kid101. The Highline. Available online: https://kid101.com/15-unique-ideas-for-parent-date-in-nyc/the-hi ghline-630x420/ (accessed on 29 March 2019).

59. CIRCARQ. High Line. 2013. Available online: https://circarq.wordpress.com/2013/05/22/high-line/ (accessed on 29 March 2019).

60. The Highline.org. High Line Art Dinner. 2018. Available online: https://www.thehighline.org/art-dinner/? (accessed on 29 March 2019).

61. Moss, J. Disney World on the Hudson. 2012. Available online: http://www.nytimes.com/2012/08/22/opinion/i n-the-shadows-of-the-high-line.html (accessed on 24 March 2019).

62. Nonko, E. Ten Development Changing the New York City Landscape. 2014. Available online: http://www.ne wyork.com/articles/real-estate/10-developments-changing-the-new-york-city-landscape-60742/ (accessed on 24 March 2019).

63. Shafray, E.; Kim, S. Approaching the issues of urban waterstreams organization as a new city landscape: Focused on Case Studied in Seoul, South Korea. J. Eng. Technol. 2016, 4, 53-58.

64. Kyriakidis, $\mathrm{C}$. The function of urban public space in relation to local parameters: Comparative study between Larisa and Nottingham. Aeichoros 2016, 24, 67-85.

65. Vlastos, T.H.; Milakis, D. Urban Planning vs Transportation. From Divergence to Convergence; ORSA; NTUA: Athens, Greece, 2006. 
66. Vlastos, T.H.; Chatzidouros, A. Cutting-edge technologies in the service of a new philosophy for public transport. In Proceedings of the Conference: Public Transportation in the Athens Metropolitan Area, Athens, Greece, 15-16 June 1998; pp. 185-193.

67. Thomas, G. A Typology for the Case Study in Social Science Following a Review of Definition, Discourse and Structure, Qualitative Inquiry. 2011. Available online: http:/qix.sagepub.com/content/17/6/511 (accessed on 4 June 2014).

68. Yin, R.K. Case Study Research: Design and Methods; Sage: Newbury Park, CA, USA, 1984.

69. Zainal, Z. Case study as a research method. J. Kemanus. 2007, 5, 1-6.

70. Hammersley, M.; Gomm, R. Introduction. In Case Study Method. Key Issues, Key Texts; Gomm, E., Hammersley, M., Foster, P., Eds.; Sage Publications: Thousand Oaks, CA, USA, 2000.

71. Bakogiannis, E.; Siti, M.; Vassi, A.; Christodoulopoulou, G.; Kyriakidis, C. Case studies and sustainable urban mobility research schemes: A communication channel among researchers and interdisciplinary community groups. Int. J. Serv. Sci. Manag. Eng. 2014, 1, 42-51.

72. Cervero, R. The Traznsit Metropolis: A Global Inquiry; Island Press: Washington, DC, USA, 1998.

73. Meyer, M.D.; Miller, E.J. Urban Transportation Planning: A Decision-Oriented Approach; McGraw-Hill: New York, NY, USA, 2001.

74. Banister, D. Unsustainable Transport: City Transport in the New Century; Routledge: London, UK, 2005.

75. Kyriakidis, C.; Bakogiannis, E. How the physical characteristics may affect the social life of streets in Athens, Greece? Eur. J. Soc. Sci. Educ. Res. 2018, 12, 15-23. [CrossRef]

76. Mourafetis, G.; Apostolopoulos, K.; Potsiou, C.; Ioannidis, C. Enhancing cadastral surveys by facilitating the participation of owners. Surv. Rev. 2015, 47, 316-324. [CrossRef]

77. Basiouka, S.; Potsiou, C.; Bakogiannis, E. Open Street Map for cadastral purposes: An application using VGI for official processes in urban areas. Surv. Rev. 2015, 47, 333-341. [CrossRef]

78. Bakogiannis, E.; Kyriakidis, C.; Siti, M.; Milioni, T.; Potsiou, C. Increasing urban resilience of Athens' Historic Center. In Proceedings of the FIG Working Week 2017, Helsinki, Finland, 29 May-2 June 2017.

79. Kyriakidis, C.; Bakogiannis, E.; Siolas, A. Identifying environmental affordances in Kypseli Square in Athens, Greece. In Proceedings of the International Conference on Social Sciences (ICONSOS) 2018, New York, NY, USA, 17-19 September 2017.

80. Giaoutzi, M.; Stratigea, A. Rural Planning: Theory and Practice; Kritiki Publications: Athens, Greece, 2011.

81. Lialios, G. Creating a Green Trail in Ilisos River. 2019. Available online: http://www.kathimerini.gr/1010757 /gallery/epikairothta/ellada/diadromh-prasinoy-me-fonto-ton-iliso (accessed on 26 March 2019).

82. Ypodomes. Syngrou Ave. The Avenue Where Large Hotel Names Are Located in 2019. Available online: https://www.ypodomes.com/index.php/alles-ypodomes/touristikes-ypodomes-tourismos/item/52 134-syggroy-i-leoforos-ton-megalon-ksenodoxeiakon-ependyseon (accessed on 28 March 2019).

83. Aixmi. Free Open-Air Cinema Every Friday in SNCC. 2016. Available online: https://www.aixmi.gr/index.p hp/dvrean-uerino-sinema-kaue-paraskeyh-sto-stayros-niarxos/ (accessed on 28 March 2019).

84. Nikolopoulos, E. Europe says "YES" in Steghi Onasis Cultural Center. 2015. Available online: https://m.eirinika.gr/article/116787/nai-stin-eyropi-leei-i-stegi-grammaton-kai-tehnon-o-politismo s-mas-enonei-agkaliazei (accessed on 28 March 2019).

85. Museum Finder. National Museum of Contemporary Art. Available online: https://museumfinder.gr/item/et hniko-mousio-sygchronis-technis/ (accessed on 28 March 2019).

86. Skyscrapercity. Goulandri Museum of Modern Art. Available online: https://www.skyscrapercity.com/sho wthread.php?p=157248754 (accessed on 28 March 2019).

87. Museum Finder. National Gallery. Available online: https://museumfinder.gr/item/ethniki-pinakothiki/ (accessed on 28 March 2019).

88. Andro. Editorial. Available online: http://www.andro.gr/apopsi/snfcc-smoking/ (accessed on 28 March 2019).

89. Ministerial Decision No 52488/2002 (FEK—Official Gazette 18B/2002): Special Arrangements for Serving the Disabled. Available online: http://www.elinyae.gr/el/lib_file_upload/b18_02.1129800988436.pdf (accessed on 30 May 2019).

90. Lynch, K. The Image of the City; MIT Press: Cambridge, MA, USA, 1960.

91. Bakogiannis, E.; Kyriakidis, C.; Siti, M.; Kourmpa, E. Support accessibility in Stavros Niarchos Foundation Cultural Center in Kallithea. In Proceedings of the 5th Pan-hellenic Conference on Planning and Regional Development, Volos, Greece, 27-30 September 2018. 
92. Strategic Plan for Transportation and Sustainable Mobility in Athens. Available online: http://www.cityofat hens.gr/node/19684 (accessed on 9 June 2019).

93. Operational Program of the Municipality of Athens (2015-2019). Available online: http://www.cityofathens .gr/node/22020 (accessed on 9 June 2019).

94. Vlastos, T.H. Tram: Feasible to function in Athens? Seven Days: Tram interventions in the past and nowadays. 2005; 16-19.

95. Stratigea, A. The concept of "smart cities". Towards community development? Netcom Netw. Commun. Stud. 2012, 26, 375-388. [CrossRef]

96. Spiropoulou, I.; Yannis, G.; Golias, J.; Karlautis, M. Impact of the Use of Developed Information Systems for Road Transport. 2016. Available online: http://library.tee.gr/digital/m2070/m2070_spiropoulou.pdf (accessed on 27 March 2019).

97. Komninos, N.; Tsarchopoulos, P. Toward intelligent Thessaloniki: From an agglomeration of Apps to smart districts. J. Knowl. Econ. 2012, 4, 149-168. [CrossRef]

98. Kang, C.D.; Cervero, R. From elevated freeway to urban greenway: Land value impacts of the CGC project in Seoul, Korea. Urban Stud. 2009, 46, 2771-2794. [CrossRef]

99. Gore, T.; Eadson, W.; Ozdemiroglu, E.; Gianferrara, E.; Phang, Z. Green Infrastructure's Contribution to Economic Growth: A Review. Project Report; Sheffield Hallam University: London, UK, 2013; Available online: http://shura.shu.ac.uk/22114/1/11406_GI_Economic_Catalyst_Final_Report_July2013.pdf (accessed on 27 March 2019).

100. Zisopoulou, A.; Kazdaglis, M. Addressing the urban heat island effect through strategic planning for promoting sustainable development in Greek cities. In Proceedings of the National Conference on Architecture, Energy and Environment of Buildings and Cities, Athens, Greece, 3-4 May 2011.

101. Huffpost. Five Most Deadly Storms That Have Taken Place in Attica. Greece Since 1895. All of Them Have Taken Place in November 2017. Available online: https://www.huffingtonpost.gr/2017/11/15/kataigides-attiki -fonikoteres-noemvrio_n_18564200.html (accessed on 27 March 2019).

102. Chung, J.H.; Hwang, K.Y.; Bae, Y.K. The loss of road capacity and self-compliance: Lessons from the Cheonggyecheon stream restoration. Transp. Policy 2012, 21, 165-178. [CrossRef]

103. NACTO. Global Street Design Guide; Island Press: New York, NY, USA, 2016.

104. Vlastos, T.H.; Barbopoulos, N.; Athanasopoulos, K. Comparative analysis of tram infrastructure in Strasburg and Athens: Initial conclusions on future implementations in Greece. In Proceedings of the 2003 International Conference on Contemporary Tram and LRT Systems, Patras, Greece, 19-20 May 2003.

105. Loughran, K. Parks for profit: Public space and inequality in New York City. City Community 2014, 13, 49-68. [CrossRef]

106. Beatley, T. Biophilic Cities. Integrating Nature into Urban Design and Planning; Island Press: Washington, DC, USA, 2011.

107. Gibson, J. An Ecological Approach to Visual Perception; Houghton Mifflin: Boston, MA, USA, 1979.

108. Tillas, A.; Vosgerau, G.; Seuchter, T.; Zipoli Caiani, S. Can Affordances Explain Behavior? Rev. Philos. Psychol. 2017, 8, 295-315. [CrossRef]

109. Whyte, W. The Social Life of Small Urban Spaces; Conservation Foundation: Washington, DC, USA, 1980.

110. Jacobs, J. The Death and Life of Great American Cities; Random House: New York, NY, USA, 1961.

111. Vlastos, T.H. Public transportation and sustainable ways of commuting. In Proceedings of the Conference: Effective Traffic Interventions That Promote the Function of Cities, Athens, Greece, 20 June 1997; pp. $33-42$.

(C) 2019 by the authors. Licensee MDPI, Basel, Switzerland. This article is an open access article distributed under the terms and conditions of the Creative Commons Attribution (CC BY) license (http://creativecommons.org/licenses/by/4.0/). 